\title{
Whole time consultants' views on private practice
}

\author{
C K BUSH, A N G CLARK
}

In January 1980 whole time contract holders in the National Health Service were allowed to undertake a limited amount of private practice after the Central Committee for Hospital Medical Services had negotiated improvements to the consultant contract. $^{1}$ This changed the position that had existed for 32 years from the beginning of the NHS. Divisive letters were published in the British Medical fournal ${ }^{2-4}$ and the Lancet $^{5-7}$ : most of them expressed antagonism to the proposal. Two years later we decided that it would be interesting to obtain the opinions and reactions by questionnaire of the 11 session contract holders in one regional health authority.

\section{Method and results}

At the time of the survey (December 1981 to March 1982) 702 consultants were employed in the South East Thames Regional Health Authority. Of these, $316(45 \%)$ in 41 specialties holding 11 session contracts were invited to complete an 18 question questionnaire. Of 310 consultants who could be contacted, $253(81.6 \%)$ replied, $39(12.6 \%)$ did not, and $18(5.8 \%)$ returned blank forms. The response rate from the 13 health districts varied from $58 \%$ to $100 \%$.

The specialties of the consultants who responded were: medical $85(33.6 \%)$; surgical and anaesthetic $50(19.8 \%)$; geriatric medicine and psychiatry $67(26.5 \%)$; and diagnostic and pathology $51(20 \cdot 2 \%)$

The first two groups were broadly labelled "acute" and the second two "mainly non-acute" for the purpose of further analysis of the replies. The median length of consultant service was 7.3 years (that for all consultants in the region was 11.2 years). One hundred and ninety one $(75.5 \%)$ were in their first 15 years as a consultant and $62(24.5 \%)$ in their second; $48(19 \%)$ held substantive or honorary sessions in teaching hospitals.

The results are given below.

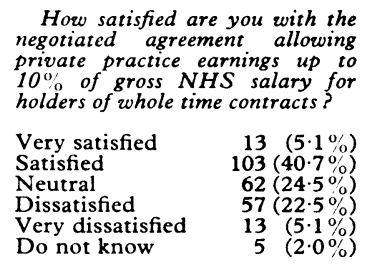

$\begin{aligned} & \text { Doyou think the 10\% rule should } \\ & \text { apply to total earnings? }\end{aligned}$
$\begin{array}{ll}\text { Yes } & 80(31.6 \%) \\ \text { No } & 74(29.2 \%) \\ \text { No preference } & 60(23.7 \%) \\ \text { Do not know } & 33(13.0 \%) \\ \text { No answer } & 6(2.4 \%)\end{array}$

Do you think the $10 \%$ limi Do you think
should be raised?

Yes

No $104(41.0 \%)$

\begin{tabular}{ll} 
No preference & $\mathbf{8 5}(33.6 \%)$ \\
\hline
\end{tabular}

Do not know $\quad 11(4.3 \%)$

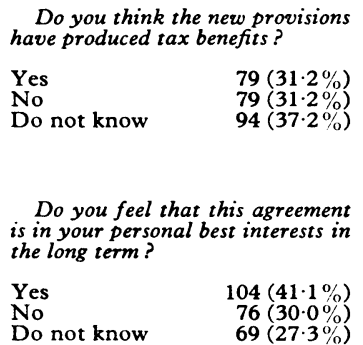

How do you rate the possibility for private practice in your locality

Very poor

Poor

Fair

Good

Very good

Do not know

$11(4.3 \%)$
$29(11.5 \%)$

$90(35.6 \%)$

$75(29.6 \%)$
$37(14.6 \%)$

$37(14.6 \%)$
$10(4.0 \%)$

Do you think there is a demand for private treatment in your
specialty in your locality?

Yes

$\begin{array}{lr}\text { No } & 189(74.7 \%) \\ \text { No } & 46(18.2 \%)\end{array}$

Do not know $\quad 16(6.3 \%)$

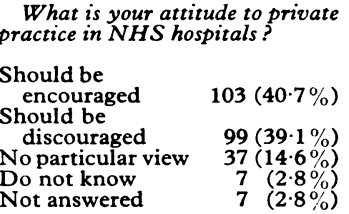

$7(2 \cdot 8 \%)$

It has been suggested that there should be a special financial allowance for whole time consultants who opt not to engage in private practice. What is your attitude to this suggestion?

Strongly disagree

Disagree

disagree

Agree

Strongly agree

Do not know

Not answered

$21(8 \cdot 3 \%)$

$34(13.4 \%)$
$71(28.1 \%)$

$71(28 \cdot 1 \%)$
$56(22 \cdot 1 \%)$

$8(3.2 \%)$
$2(0.8 \%)$ If there is an increase in the total
number of consultant posts what do nou think of consult be the effect on the
you demand for private treatment

$\begin{array}{lr}\text { Demand will } & \\ \text { increase } & 27(10.7 \%) \\ \text { Demand will lessen } & 72(28.5 \%) \\ \text { No effect } & 100(39.5 \%) \\ \text { Do not know } & 52(20.6 \%)\end{array}$
East Surrey Health Authority, Earlswood Mount, Redhill, Surrey
RH1 6JT

C K BUSH, MSC, BA, principal administrative assistant, service planning administrative support

\section{Brighton General Hospital, Brighton BN2 3EW}

A N G CLARK, MD, FRCP, consultant in geriatric medicine

Correspondence and requests for reprints to: Dr A N G Clark.

\section{Discussion}

The high rate of response to the survey suggests that private practice is still of great interest to consultants holding whole time contracts. There are good opportunities for private practice in the region surveyed.

Most of the respondents $(45.8 \%)$ seemed satisfied with the $10 \%$ private practice now allowed, but a substantial minority $(27.6 \%)$ remained opposed to it. "Extra income" (25.4\%) and "more personal freedom" $(16.4 \%)$ were the most common 
responses given by those satisfied. Less tangible positive reasons were "it is a step forward," "removal of restrictions," and "a reasonable compromise." Of the satisfied respondents, $16.2 \%$ gave a negative response stating that they could not earn more than, or as much as, $10 \%$ from private practice. Ten and a half per cent did not provide reasons for satisfaction. Inability to do private practice was the main reason given by the equivocal group.

More clearcut reasons were given for dissatisfaction: " $10 \%$ limit too low" $(28.7 \%)$, and "inability to practise privately" $(20.0 \%)$. Some thought that the concession would erode future salary levels and that the proposals had brought more benefit to 10 session holders, or discriminated against those unable, or not wishing, to do private practice.

There was less certainty about possible long term benefits: $41.1 \%$ supported the scheme, $30 \%$ opposed it, and $27.3 \%$ were unable to express an opinion. There were equal proportions of respondents in their first and second 15 years of service in the answers to this question. When divided by specialty more in the "non-acute" specialties $(58.9 \%)$ were not able to agree that the change was beneficial compared to "acute" specialists $(59 \cdot 6 \%)$ who thought that it was.

An equal division of opinion was found regarding the value of tax benefits. The fact that more than a third of respondents were unable to answer the question showed that many consultants were not aware what these benefits were. Clearly some doctors do not realise that general taxation advice is available to members from the British Medical Association or, presumably, that the British United Provident Association runs occasional two day courses on entry into private practice for senior registrars and young consultants. Of those consultants who said that the new provisions had produced tax benefits, $21(8.3 \%)$ thought these were very slight, $37(14.6 \%)$ slight, $22(8.7 \%)$ fair, and three $(1.2 \%)$ substantial.

Most respondents $(73.8 \%$ ) thought that there were fair to very good opportunities for private practice in their area, with a similar figure for opportunity in respect of specialty. A good view was more common in the "acute" specialties, and those areas with little demand showed a higher than average proportion of whole time consultants.

The responses showed that in certain areas if there is a demand for private treatment it is in most specialties (or at any rate in those in which private practice is possible); otherwise the demand is not there at all.

A similar polarisation of view was apparent on the principle of private practice in NHS hospitals. More "non-acute" specialists $(47 \cdot 3 \%)$ were against, while one in two of the "acute" specialists $(36.3 \%)$ thought that it should be encouraged. The reasons were listed under 29 headings, the most common being: reducing travel, improving NHS income, possible abuse, the value of separation, better facilities for the very ill. Some consultants who were not opposed nevertheless judged that there was now an irreconcilable gulf between the two sectors.

Half the sample agreed with the concept of the whole time commitment allowance and one third disagreed, with no differences by length of service or specialty. Those who opposed such an allowance supported private practice and those in favour were against it in NHS hospitals. Many saw the principle as fair, some opposing it as a payment not related to work done.

The CCHMS, which argued forcefully in the recent reorganisation to keep consultant contracts at regional level (with the exception of teaching hospitals), will be encouraged that the most unanimous view-211 $\left(87 \cdot 2_{0}^{\circ}\right)$-on any one subject supported contracts being held by regional health authorities. Only $10(4 \%)$ thought that this was wrong.

Many different attitudes and views were seen in the comments that these questions produced. Two fifths of the sample said that they did not undertake private practice or had no opportunity to do so. Some strongly supported fees from patients professionally (or on professional grounds), others feeling disquiet about payment. Although some were opposed to

\section{Revised consultant contract}

Modifications to the consultant contract were agreed in principle in September 1979, the DHSS circular (PM(79)11) was issued in November, and the modifications set out below were implemented on 1 January 1980.

- Whole time consultants are allowed a limited right to private practice to the extent of $10 \%$ of their NHS salary (including distinction awards, if applicable).

- Whole time consultants and those with nine session contracts are allowed an additional paid session, where needs of the service require.

- Consultants with maximum part time contracts are to be paid $10 / 11$ ths of the whole time salary.

- Maximum part time consultants who want to limit their NHS commitments will, exceptionally, be offered a nine session contract.

- Those consultants who have retained a nine session contract may opt for a maximum part time contract within three months of the date of implementation.

this on professional and political grounds, the survey showed some support, or toleration, for private practice for whole time consultants.

Support for a whole time commitment payment from two thirds of consultants suggested that many consultants thought that this was fair. Some wished to see closer links between private practice and the NHS but others thought that this would be unwise in view of the opposition of ancillary workers.

Those who believe that consultants have been tardy in supporting a policy to increase their numbers because of fears that it would reduce the demand for private practice might be surprised that half the respondents forecast no fall in demand if consultant numbers were increased.

\section{Conclusion}

After two years the new contract still stimulates controversy, with views diverging sharply on the basic issues. Consultants' attitudes seem to be determined by a combination of professional, political, and practical factors, illustrating how difficult it is to formulate a single contract that is satisfactory for everyone. Clearly, the ideal contract should not be coercive and should take into account the different circumstances of the individual. The varying opportunities in the different disciplines mean that flexibility and fairness are required to provide sufficient options and alternatives.

We should like to thank the South East Thames Regional Health Authority for access to information and the University of Surrey for providing facilities for data analysis.

\section{References}

1 Anonymous. Consultant contract. Government approves proposals Br Med F 1979; ;i :685-6.

Ross BA. CCHMS proposals. Br Med 7 1979;ii:503.

3 Gough MH. Destroying the whole time option. Br Med f 1979; ii :554.

- Ashley D. Consultant contract proposals. Br Med $\mathcal{f}$ 1979;ii:868-9.

Revill MG. The new consultant contract. Lancet 1979;ii:1150.

Simmons NA. Consultant contract. Lancet 1979;ii:1296.

` Noone P. New consultant contract. Lancet 1979;ii:1405.

(Accepted 19 April 1983)

Published by the Proprietors, THE BRITISH MEDICAL ASSOCIATION, Tavistock Square, London WC1H 9JR, and printed in Great Britain by George Pulman and Sons Limited of London and Bletchley, Typesetting by Bedford Typesetters Limited, Bedford. 